$\xi=-1$

\title{
Dynamic loading of electric machines during testing
}

\author{
Sergey I. Malafeev ${ }^{1 *}$, Sergey S. Malafeev ${ }^{2}$ \\ ${ }^{1}$ Joint Power Co, Ltd, Moscow, Russia \\ ${ }^{2}$ Vladimir Polytechnical College, Vladimir, Russia \\ *E-mail: sim_vl@nm.ru
}

\begin{abstract}
An energy-efficient and simple method of testing electric motors in a dynamic mode is considered. When testing an electrical machine, the rotor is driven into a reciprocating rotary motion. The source of power of the power converter, which controls the electric machine, is a supercapacitor. When the electric machine is accelerated, electric energy is consumed from the supercapacitor, when the machine brakes the kinetic energy of the moving masses is converted into electrical energy, which accumulates in the supercapacitor. The energy loss during the operation of the electromechanical system in the dynamic mode is compensated by recharging the supercapacitor using a controlled rectifier connected to the power supply network.
\end{abstract}

Keywords: Electric Motor; Supercapacitor; Test; Energy; Converter

\section{Introduction}

Electric machines are currently the main consumers of electrical energy [1]. Tests of electrical machines are performed to determine their characteristics during production, after repairs and during operation [2]. Labor costs for electrical motor testing are estimated at $13 \%$ of the cost of manufacturing them. In this case, the processes of long-term testing have low energy efficiency [4]. The main tests of the motors are performed in a static mode under load. At high motor power, the tests are carried out by the method of mutual loading (returning work). In this case, two machines are tested simultaneously: one is running in the motor mode, the other is in the generator mode. For such tests, in most cases, for example, for vertical motors, special sophisticated equipment is required [5]. When a dynamic load is used to test electric machines, a voltage is applied to the stator of the machine, causing a reciprocating rotary motion of the rotor [6]. The energy state of the tested motor and the power supply network is characterized by energy-exchange processes in the electric machine-network system. When the machine is accelerated, electric energy is consumed from the network, when the machine brakes, the kinetic energy of the rotating masses is recuperated into the power network. As consumption and recovery processes occur alternately, such tests are characterized by low energy efficiency. In the acceleration mode, a lot of power is consumed, with the recuperation, the use of the returned energy leads to an increase in the voltage at the point where the load is connected. The periodic process of energy consumption and recuperation causes voltage fluctuations in the network and an increase in the losses of electrical energy. In this case, the effective use of recovered energy is possible only if there is an appropriate power in the receiver network. In [7] methods of testing a group of electric machines by the method of artificial loading with a controlled process of energy exchange between generators and motors are considered.

In this paper, we consider the method of dynamic loading of electric motors using an electric energy storage device.

\section{The method of testing electric machines in a dynamic mode}

In Fig. 1 shows a simplified functional diagram of an installation for testing electric machines in a dynamic mode [8]. The installation contains a transformer connected to the mains power supply and a controlled rectifier connected to the secondary winding of the transformer. The DC link contains a supercapacitor $C$ and a choke $L$ that performs the function of a higher harmonics filter. A reversible energy converter provides the supply voltage for the motor. The energy converter is controlled by a controller. The flywheel is mounted on the motor shaft.

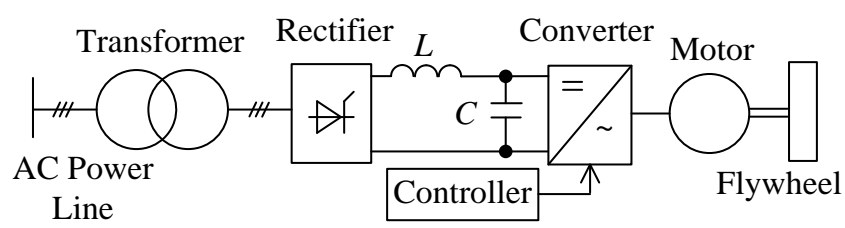

Fig. 1: Simplified diagram of testing electric machines in a dynamic mode

The test of an electric motor in a dynamic mode is as follows. The supercapacitor $C$, connected to the output of the controlled rectifier through the throttle, operates in the recharge mode [9]. It uses a controlled rectifier to maintain a constant voltage. The choke provides a reduction in the variable component of the charge current of the supercapacitor $C$. The controller generates alternating control voltage for the reversible energy converter. A controlled reversible energy converter generates the supply voltage of the motor $\mathrm{M}$, which ensures its reciprocating rotary motion due to the energy stored in the supercapacitor. When the 
motor rotates in the same direction, i.e. when accelerating to the maximum angular speed $\Omega_{m}$, kinetic energy is accumulated in the flywheel and rotor of the motor.

When the direction of rotation of the motor is changed, the rotating masses are braked and the mechanical energy is converted into electrical energy, which is returned to the supercapacitor. Then the cycle repeats. The motor load is controlled by the frequency and amplitude of the oscillations.

The energy losses in the elements of the reversing converter and the motor are compensated for by the charge of the supercapacitor from the supply network. Thus, the consumption of energy from the supply network during the testing of an electrical machine is determined by losses in the elements of the system and is $5 . .20 \%$ of the power of the electrical machine under test.

In the simplest case of tests, the oscillatory motion of the rotor of an electric machine occurs according to a harmonic law with a speed

$$
\Omega(t)=\Omega_{m} \sin (2 \pi f t) \text {. }
$$

Here $\Omega_{m}$ is amplitude of the angular velocity; $f$ is frequency of the oscillations.

The kinetic energy of the oscillating mass (rotor and flywheel) varies according to the law

$W_{k}=\frac{J \Omega_{m}^{2}}{2} \sin ^{2}(2 \pi f t)=\frac{J \Omega_{m}^{2}}{4}[1-\cos (4 \pi f)]$,

here $J$ is the total moment of inertia of the flywheel and rotor of the motor.

The maximum value of the kinetic energy are

$W_{k m}=\frac{J \Omega_{m}^{2}}{2}$.

Electrical energy of the supercapacitor are

$W_{e}=\frac{C U^{2}(t)}{2}$,

here $C$ is capacity of the capacitor; $U(t)$ is a voltage on the capacitor.

There are various variants of the organization of the oscillation regime during testing. For example, oscillatory motion of a rotor with a constant velocity component without a reverse, twofrequency oscillations, etc.

The technical implementation of a reversible energy converter is determined by the type of electrical machine. For the testing of DC electric machines, a transistor direct current transducer with pulse-width control is used as a reversible energy converter [10] In Fig. 3 shows a diagram of the power part of a four-quadrant converter for direct-current motor control. The circuit uses 4 keys on the IGBT-transistors with PWM control.

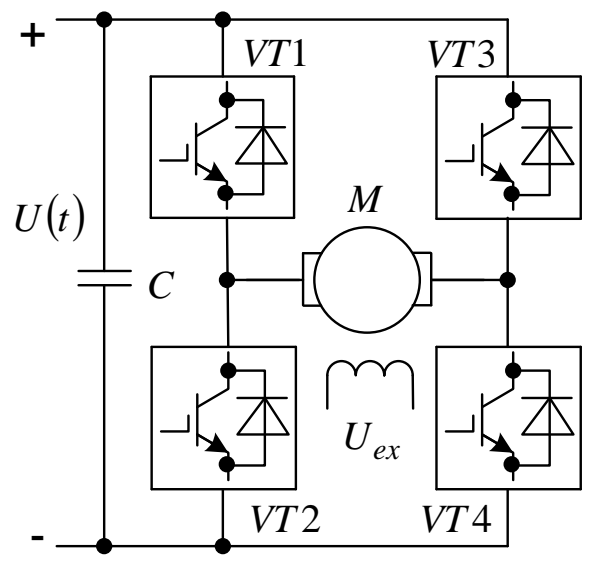

Fig. 3: The converter circuit for controlling DC motor
For the testing of electric alternating current machines, for example, asynchronous motors, a three-phase bridge transistor inverter is used as a reversible energy converter [10]. In Fig. 4 shows a diagram of the power part of a three-phase inverter on IGBT-transistors with PWM control.

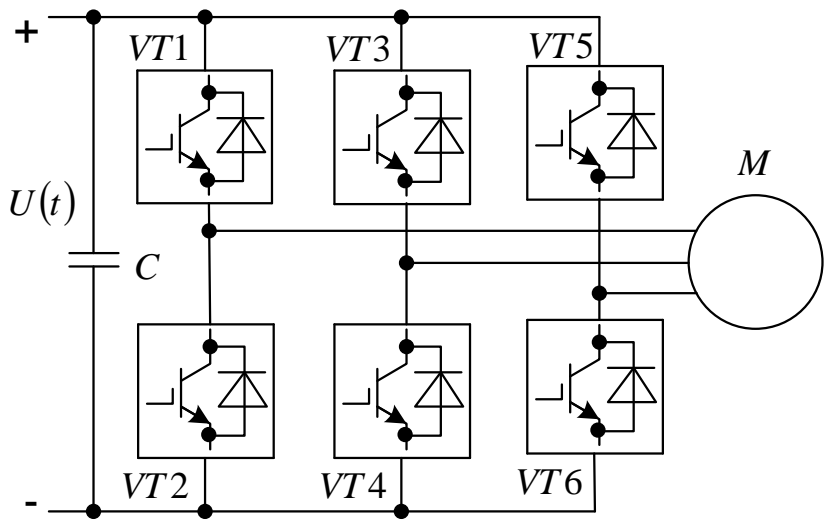

Fig. 4: The converter circuit for controlling induction motor

Thus, the considered method provides an increase in the energy efficiency of testing electric machines by using the recuperated energy when braking the rotating masses directly for the subsequent acceleration of the machine with the flywheel.

\section{Modeling of the motor test system in dynamic mode}

Computer simulation of the test system is performed in the MATLAB system for an asynchronous motor. The motor parameters had the following values: power - $400 \mathrm{~kW}$; voltage (line to line) - $380 \mathrm{~V}$; the rated speed is $950 \mathrm{rpm}$. The supply network is $380 \mathrm{~V}, 50 \mathrm{~Hz}$. The capacity of the supercapacitor is 10 F. The moment of inertia of the flywheel is $30 \mathrm{~kg} \cdot \mathrm{m}^{2}$. The duration of the cycle of the return-rotational motion is $8 \mathrm{~s}$.

To control the induction motor, a three-phase inverter with vector control is used [11].

In Fig. 5 - Fig. 8 shows the results of modeling the system that realizes the process of testing the motor with a harmonic oscillatory mode. The diagrams of electrical $P_{e}$ and mechanical $P_{m}$ powers of the motor are shown in the Fig. 5. In the Fig. 6 are shown the diagrams of the current at the output of rectifier $i_{R}(t)$ and input of the inverter $i_{\text {con }}(t)$ and voltage $U(t)$ at the supercapacitor.



Fig. 5: Diagrams of the electrical $P_{e}$ and mechanical $P_{m}$ power of the motor

The diagrams of the change in the kinetic energy of the flywheel and the electric energy of the engine are shown in Fig. 7. 


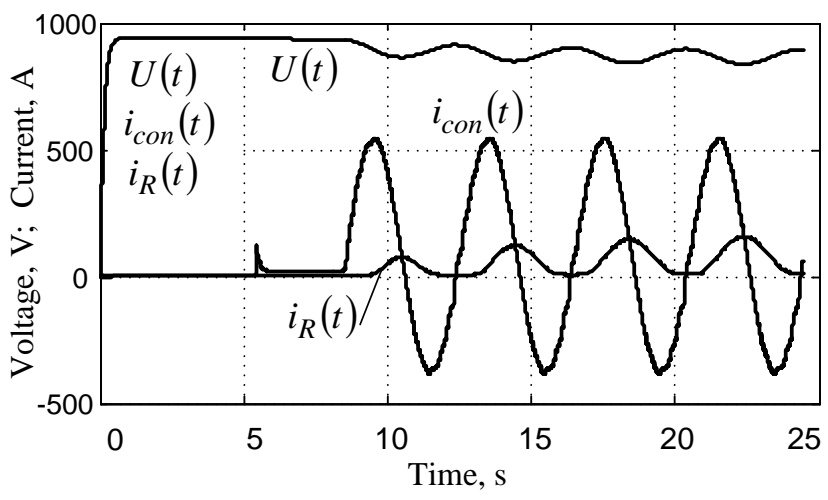

Fig. 6: Diagrams of the processes in the DC link: $U(t)$ - voltage at the supercapacitor; $i_{R}(t)$ - current at the output of the rectifier; $i_{c o n}(t)$ current at the input of the inverter

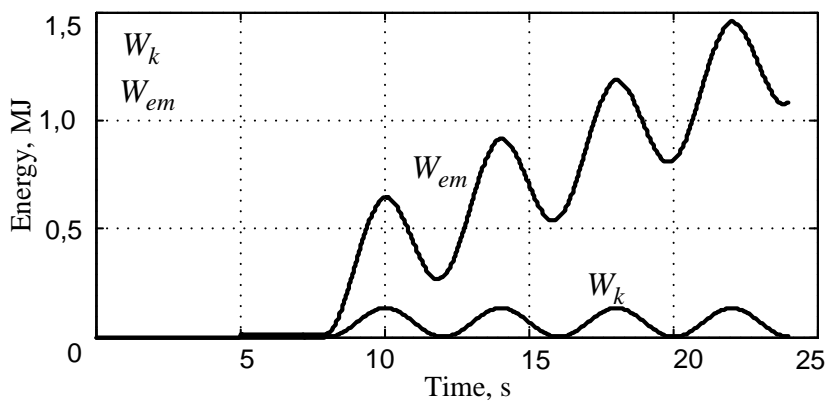

Fig. 7: Diagrams of the energy processes: $W_{k}$ - kinetic energy of the oscillating masses; $W_{\text {em }}$ - electric energy consumed by the engine



Fig. 8: Diagrams of the consumption of electric energy in the system without a supercapacitor (line 1) and with a supercapacitor (line 2)

The mechanical energy is calculated by the formula

$$
W_{e m}=\int_{0}^{t} M_{e}(t) \Omega(t) d t
$$

here $M_{e}(t)$ - electromagnetic torque of the motor.

The mechanical energy consumed by the electric machine in the motor mode is $0.7 \mathrm{MJ}$ per cycle. The energy recuperated by braking the machine is $0.4 \mathrm{MJ}$.

In Fig. 8 are shown diagrams of energy consumption from a rectifier without a supercapacitor and with a supercapacitor. When using a $10 \mathrm{~F}$ supercapacitor, the energy consumption from the source per cycle are $0.48 \mathrm{~J}$. Energy savings during testing are $76 \%$. Increasing the efficiency of using electric energy is achieved by choice of vibration frequency, moment of inertia of the flywheel and capacity of the supercapacitor. When the period of oscillations is increased by a factor of 2 (16 s) the energy consumption from the source is $0.1 \mathrm{MJ}$ per cycle. Thus, the power of an electric machine operating alternately in the motor and generator modes is $143 \mathrm{~kW}$. The power consumed from the mains is $10 \mathrm{~kW}$, that is $7 \%$ of the power of the electric machine during testing.

\section{Conclusion and future work}

The paper presents a solution to the problem of efficient energy use in the testing of electric machines under load. The considered method of testing electric motors ensures the high energy efficiency of carrying out long-term experiments. In this case, the power part of the installation has a simple design. The motor load is changed by adjusting the oscillation parameters. Measurement and processing of the parameters of the oscillation mode allows obtaining additional information on losses in the motor during dynamic operation, including during energy recuperation. The technique is designed for testing DC and AC motors.

The purpose of further research is to modify the method considered for testing electric motors operating in a cyclic mode by simulating a real load. A stand is being developed for testing $\mathrm{DC}$ and $\mathrm{AC}$ motors for mine excavators.

Of great interest is the use of the method of dynamical testing of motors in oscillatory mode to study the losses in individual drive components in different modes [12].

\section{References}

[1] Hanitsch R. "Energy Efficient Electric motors". RIO-02 - World Climate \& Energy Event, January 6-11, 2002, pp. $45-50$.

[2] Deshpande M.V. Design and Testing of Electrical Machines. Published by Asoke K. Grosh, PHI Learning Private Limited, New Delhi. ISBN: 978-81-203-3645-2.

[3] McKinnon D.J., Seyoum D. and Grantham C. "Investigation of parameter characteristics for induction machine analysis and control", Conf. Proc. of the Second International Conference on Power Electronics, Machines and Drives, (PEMD 2004), University of Edinburgh, UK, 31 Mar. - 2 Apr. 2004, pp. 320 325

[4] Beierlein E.V. and Tyuteva P.V. "Energy-saving Technology for Testing of Traction Induction Motors", XVII Modern Technique Technologies 2011, pp. 44-46.

[5] Boldea I., Tyuteva L. and Klumpner C. "Artificial loading of induction machines: a review", Workshop on Electrical Machine's Parameters. Technical University of Cluj-Napoca, $26^{\text {th }}$ of May, 2001, pp. $9-14$.

[6] Loayza Y., Reinap A. and Alakula M. "Performance and efficiency evaluation of FPGA controlled IPMSM under dynamic loading, Diagnostics for Electric Machines", Power Electronics \& Drives (SDEMPED), 2011 IEEE International Symposium, Bologna, Italy, 5-8 Sept. 2011, pp. $550-555$, Electronic ISBN: 978-1-4244-9303-6, doi: 10.1109/DEMPED.2011.6063677.

[7] Deaconu S.I., Tutelea L.N., Popa G.N. and Latinovic T. "Artificial loading for Rotating Electric Machines", Annals of Faculty Engineering Hunedoara - International Journal of Engineering. Tome IX (Year 2011). Fascicule 1. ISSN 15942665, pp. $213-218$.

[8] Malafeev S.I. "Test Bench of Electrical Machines in Dynamic Mode”. Pat. RU № 2561230. Int. Cl. G01R31/34. Date of publication: 27.08.2015. Bull. № 24.

[9] Halper M.S. and Ellenbogen J.C. Supercapacitors: A Brief Overview, MITRE, McLean, Virginia, March 2006, 41 p.

[10] Bose B.K. Modern Power Electronics and AC Drives, Prentice Hall PRT, 2002, 738 p. ISBN: 0-13-016743-6.

[11] Malafeev S.I. and Zaharov A.V. "Investigation of Losses taking place in an induction motor with frequency control during transient processes", Russian Electrical Engineering, 2008, V. 79, No 7: 349 - 352; https://doi.org/10.3103/s1068371208070018.

[12] Malafeev S.I., Kopeykin A.I. and Malafeev S.S. "Investigation of the characteristics of friction pairs in the oscillation regime: the method and implementation of the mechatronic oscillatory 
system". Proceedings of BALTTRIB'2017 edited by prof. J.

Padgurskas. eISSN 2424-5088/eISBN 978-609-449-039-4. 2017,

p. 137 - 142. https://doi.org/10.15544/balttrib.2017.25 